\title{
Nasal highflow improves ventilation in patients with COPD
}

\author{
This article was published in the following Dove Press journal: \\ International Journal of COPD \\ 25 May 2016 \\ Number of times this article has been viewed
}

\section{Jens Bräunlich* \\ Marcus Köhler* \\ Hubert Wirtz}

Department of Respiratory Medicine, University of Leipzig, Leipzig,

Germany

*These authors contributed equally to this work
Correspondence: Jens Bräunlich Department of Respiratory Medicine, University of Leipzig, Liebigstrasse 20 , 04103 Leipzig, Germany

Tel +49 34I 97| 2450

Email jens.braeunlich@uniklinik-leipzig.de
Background: Nasal highflow (NHF) provides a warmed and humidified air stream up to $60 \mathrm{~L} / \mathrm{min}$. Recent data demonstrated a positive effect in patients with acute hypoxemic respiratory failure, especially when caused by pneumonia. Preliminary data show a decrease in hypercapnia in patients with COPD. Therefore, NHF should be evaluated as a new ventilatory support device. This study was conducted to assess the impact of different flow rates on ventilatory parameters in patients with COPD.

Materials and methods: This interventional clinical study was performed with patients suffering from severe COPD. The aim was to characterize flow-dependent changes in mean airway pressure, breathing volumes, breathing frequency, and decrease in partial pressure of $\mathrm{CO}_{2}\left(\mathrm{pCO}_{2}\right)$. Mean airway pressure was measured in the nasopharyngeal space (19 patients). To evaluate breathing volumes, we used a polysomnographic device (18 patients). All patients received $20 \mathrm{~L} / \mathrm{min}, 30 \mathrm{~L} / \mathrm{min}, 40 \mathrm{~L} / \mathrm{min}$, and $50 \mathrm{~L} / \mathrm{min}$ and - to illustrate the effects - nasal continuous positive airway pressure and nasal bilevel positive airway pressure. Capillary blood gas analyses were performed in 54 patients with hypercapnic COPD before and two hours after the use of NHF. We compared the extent of decrease in $\mathrm{pCO}_{2}$ when using $20 \mathrm{~L} / \mathrm{min}$ and $30 \mathrm{~L} / \mathrm{min}$. Additionally, comfort and dyspnea during the use of NHF were surveyed.

Results: NHF resulted in a minor flow dependent increase in mean airway pressure. Tidal volume increased, and breathing rate decreased. The calculated minute volume decreased under NHF breathing. In spite of this fact, hypercapnia decreased with increasing flow $(20 \mathrm{~L} / \mathrm{min}$ vs $30 \mathrm{~L} / \mathrm{min}$ ). Additionally, an improvement in dyspnea was observed. The rapid shallow breathing index shows a decrease when using NHF.

Conclusion: NHF leads to a flow-dependent reduction in $\mathrm{pCO}_{2}$. This is most likely achieved by a washout of the respiratory tract and a functional reduction in dead space. In summary, NHF enhances effectiveness of breathing in patients with COPD, reduces $\mathrm{pCO}_{2}$, the work of breathing, and rapid shallow breathing index as an indicator of respiratory work load.

Keywords: NHF, hypercapnia, nasal high flow cannula, $\mathrm{pCO}_{2}$, ventilation

\section{Introduction}

Despite significant improvements in bronchodilator therapy, and the possibility of long-term oxygen therapy, COPD may ultimately lead to a need for ventilatory support. Noninvasive ventilation (NIV) has not only been proven to be extremely useful in situations of acute exacerbation of COPD but also been used in chronic hypercapnic COPD for several years. However, effectiveness in chronic hypercapnia remains controversial as demonstrated in recent meta-analyses. ${ }^{1,2}$ Other reports suggest benefits by increasing positive inspiratory pressure. ${ }^{3,4}$ In a very recent study, a reduction in partial pressure of $\mathrm{CO}_{2}\left(\mathrm{pCO}_{2}\right)$ was demonstrated in addition to an improved 1 year mortality. ${ }^{5}$ 
However, NIV via a face mask is not tolerated by every patient due to a variety of side effects, such as claustrophobia, skin rash, eye irritation, and clinical failure. ${ }^{6-11}$ So far, there is no established alternative for patients who do not tolerate standard NIV. Nasal highflow (NHF) is an emerging technique that may also be used to support ventilation and simultaneously provide an extended range of oxygen concentrations when needed. ${ }^{12-18}$

Several new studies suggest the effectiveness of NHF in patients with acute hypoxemic respiratory failure. Maggiore et $\mathrm{al}^{19}$ compared NHF to oxygen application via a Venturi mask in patients following extubation. They demonstrated improvements in ventilatory parameters with NHF. Frat et al compared NHF with NIV and oxygen therapy in a similar patient population. Surprisingly, these authors found a lower 90-day mortality rate and a decrease in intubation rates with NHF in patients suffering from severe hypoxic respiratory failure. ${ }^{20}$ Some studies describe a reduction in breathing rate (BR) and heart rate, decreased dyspnea, and the improvement of oxygenation in acute respiratory failure. ${ }^{21-24}$

NHF may also be considered for adult patients with chronic respiratory failure due to, for instance, COPD, although there is little evidence yet supporting this hypothesis. Two studies in patients with hypercapnic respiratory failure revealed a decrease in capillary $\mathrm{pCO}_{2}$ with $\mathrm{NHF}$ breathing $(20 \mathrm{~L} / \mathrm{min}) .{ }^{17,18}$ The investigators also observed a decrease in BR and minute volume. ${ }^{17}$

Increases in airway pressure have been suggested to explain the effects of NHF. ${ }^{25-28}$ The study by Frizzola et $\mathrm{al}^{29}$ using piglets, however, resulted in the realization that a decrease in $\mathrm{pCO}_{2}$ with NHF is not due to pressure changes but rather due to changes in flow rate and upper airway leakage.

There is no available information on flow rate-dependent effects on ventilatory parameters, clinical benefits, and influences on hypercapnia in patients with COPD. In the present study, the effects of different levels of NHF rates were investigated in patients with COPD.

\section{Materials and methods Devices}

In this study, we used the TNI softflow 50 device (TNI medical AG, Wuerzburg, Germany). NHF was applied using nasal prongs with different bore outlets (TNI medical AG) in order to apply the intended elevated flow rates. Small, medium, and large sizes of nasal prongs were compared as a part of the study. The nasal bilevel positive airway pressure (nBiPAP) and nasal continuous positive airway pressure (nCPAP) were applied using a nose mask (BiPAP
Synchrony; Philips Respironics, Andover, MA, USA) because of faster adaptation during measurement. The aim was to illustrate different modes of action between NHF and nCPAP/nBiPAP. Therefore, we applied lower pressures than used in daily practice.

\section{Patients}

A total of 67 hospitalized patients with COPD (GOLD C/D) were recruited from the respiratory ward at the University Hospital of Leipzig from April 2015 to December 2015. The study was approved by the ethics committee of University of Leipzig (414-14-06102014) and registered (ClinicalTrails NCT02504814). Patients provided written informed consent including their participation in the trial and the use of their data for analysis. All patients were in stable conditions without acute exacerbation or right heart decompensation.

The aim of this study was to characterize flow ratedependent ventilatory effects and changes in hypercapnia in an interventional and clinical setting. Outcome parameters included changes in mean airway pressure, tidal volume (VI), and breathing frequency. The end point in hypercapnic patients was decrease in $\mathrm{pCO}_{2}$.

\section{Measurement of airway pressure}

A water-filled flexible tube (inner diameter $1 \mathrm{~mm}$, Original Perfusor $^{\circledR}$-cable type standard; B. Braun, Melsungen, Germany) was placed in the nasopharyngeal space and then used as pressure transducer. A pressure sensor (GMH3111; Greisinger Electronic GmbH, Regenstauf, Germany) connected to a laptop was used to record the signal. Ten breaths were recorded during spontaneous breathing, NHF breathing, and nCPAP/nBiPAP breathing. In 19 patients with COPD, the mean airway pressure was measured in a sitting body position. Pressure during spontaneous breathing defined baseline pressure (zero). Measurements were performed and repeated with different prong sizes (small, medium, and large).

\section{Measurement of VT, BR, and minute volume}

Sensor belts and a polysomnograph (Respitrace; CareFusion GmbH, Höchberg, Germany) were used to measure VTs. Patients were measured in a sitting position. Elastic sensor belts were placed $10 \mathrm{~cm}$ below the jugular notch and $10 \mathrm{~cm}$ below the xiphoid process, and VT measurements were performed. Subsequently, we calibrated the device individually for each patient starting with "normal" tidal breathing, which was recorded with standard lung function equipment (Master Screen Body; CareFusion GmbH). While measuring VTs of 
ten breaths and simultaneously registering the sensor signal, we were able to calibrate the sensor belt signal to changes in lung volume. Following calibration, volume measurements during NHF and spontaneous breathing were started. Chest and abdominal excursions were recorded, and volumes were calculated. BRs and VTs were measured in 18 patients with COPD. Minute volumes were calculated. Measurements were performed and repeated with different prong sizes (small, medium, and large).

\section{Rapid shallow breathing index}

To obtain a work of breathing parameter, the rapid shallow breathing index (RSBI) was calculated. Calculations were done as follows

$$
\text { RSBI: breaths per min/VT (L) }
$$

\section{Comfort and dyspnea scale}

Subjective patient comfort was correlated with various prong sizes and the use of nCPAP and nBiPAP. We used a simple dyspnea and comfort scale to evaluate patient satisfaction. Differences between flow and pressure settings were not compared because of the short application time. The comfort scale ranged from 1 to 10 and the dyspnea scale from 1 to 5 . A smaller number defined a more comfortable ventilatory support or less dyspnea.

\section{Blood gas analysis}

A total of 54 patients with chronic ventilatory insufficiency and hypercapnia were treated with different flows $(20 \mathrm{~L} / \mathrm{min}$ and $30 \mathrm{~L} / \mathrm{min}$ ). Capillary blood gases were taken from the earlobe 10 minutes after applying a hyperemia-inducing ointment (Finalgon ${ }^{\circledR}$; Boehringer Ingelheim, Ingelheim, Germany). Measurements were performed under constant oxygen supplementation before and 2 hours after NHF breathing.

\section{Statistics}

Data were analyzed using Student's $t$-test and linear regression analysis (Sigma Plot; Systat Software GmbH, Ekrath, Germany). A probability level for the null hypothesis (no difference) of $<5 \%(P<0.05)$ was accepted for significance. The results were expressed as mean values. Changes compared to baseline values were expressed in percent because of variance in values. In statistical analysis, measurements were compared with baseline and nearby flow rates, respectively. $P$ values were generated using percentage changes.

\section{Results}

Demographic data of patients are listed in Table 1.

\section{Changes in mean airway pressure}

During NHF breathing, mean airway pressure increased in a flow dependent manner (Figure 1). A flow of $20 \mathrm{~L} / \mathrm{min}$ resulted in a significant increase in mean airway pressure $(0.92 \pm 0.49$ mbar; $P<0.05)$ in comparison to spontaneous breathing. When increasing the NHF rate up to $50 \mathrm{~L} / \mathrm{min}$, the mean airway pressure increased further to $3.01 \pm 1.03$ mbar. An increase of $10 \mathrm{~L} / \mathrm{min}$ resulted in a significant mean increase of 1.4-1.6-fold. Prong size did not result in significant pressure differences at a constant flow. The results depicted in graphs were measured with patients using the medium-sized prongs (diameter $4.9 \mathrm{~mm}$ ). Mean airway pressures were increased during breathing with $\mathrm{nCPAP}$ and

Table I Demographic data

\begin{tabular}{|c|c|c|c|c|}
\hline & $\begin{array}{l}\text { (A) Pressure } \\
\text { group }(n=19)\end{array}$ & $\begin{array}{l}\text { (B) Volume } \\
\text { group }(n=18)\end{array}$ & $\begin{array}{l}(\mathrm{C}) \mathrm{PCO}_{2} \\
\text { group }(\mathrm{n}=54)\end{array}$ & $\begin{array}{l}\text { P-value (A/B; } \\
\text { B/C;A/C) }\end{array}$ \\
\hline Age (years) & $60.0 \pm 11.4$ & $60.1 \pm 11.0$ & $61.2 \pm 11.3$ & $0.8 ; 0.2 ; 0.2$ \\
\hline Sex ratio (women:men) & $\mathrm{I}: 2.8$ & $\mathrm{I}: 2.4$ & $1: 1.25$ & nd \\
\hline BMI $\left(\mathrm{kg} / \mathrm{m}^{2}\right)$ & $23.4 \pm 4.5$ & $23.3 \pm 4.7$ & $23.9 \pm 5.7$ & $0.9 ; 0.6 ; 0.7$ \\
\hline FVC (\% pred) & $66.4 \pm 25.5$ & $64.1 \pm 23.8$ & $52.7 \pm 22.5$ & $0.8 ; 0.06 ; 0.04$ \\
\hline $\mathrm{FEV}_{1}$ (\% pred) & $42.9 \pm 23.5$ & $41.4 \pm 22.0$ & $35.1 \pm 18.6$ & $0.8 ; 0.2 ; 0.2$ \\
\hline FEV,/FVC (\%) & $52.0 \pm 13.3$ & $51.4 \pm 12.6$ & $51.0 \pm 13.6$ & $0.9 ; 0.9 ; 0.8$ \\
\hline$R_{\text {tot }}(\%$ pred $)$ & $233.8 \pm 121.4$ & $242.6 \pm 125.8$ & $331.4 \pm 197.3$ & $0.8 ; 0.05 \mathrm{I} ; 0.054$ \\
\hline TLC (\% pred) & $118.3 \pm 19.6$ & $115.3 \pm 19.3$ & $114.4 \pm 21.3$ & $0.6 ; 0.9 ; 0.5$ \\
\hline RV/TLC (\% pred) & $|74.0 \pm 40|$. & $173.7 \pm 38.5$ & $|8| .| \pm 43|$. & $0.9 ; 0.5 ; 0.6$ \\
\hline 6-MWT (m) & $220 \pm 117.6$ & $212.9 \pm 109.2$ & $196.9 \pm 134.4$ & $0.9 ; 0.7 ; 0.6$ \\
\hline Capillary $\mathrm{pCO}_{2}(\mathrm{mmHg})$ & $49.1 \pm 11.5$ & $48.0 \pm 12.1$ & $58.2 \pm 13.8$ & $0.8 ; 0.004 ; 0.02$ \\
\hline
\end{tabular}

Note: $P$-value calculation with Student's $t$-test (two-sample).

Abbreviations: 6-MWT, 6-minute walk test; $\mathrm{BMI}$, body mass index; FVC, forced vital capacity; $\mathrm{FEV}_{1}$, forced expiratory volume in I second; nd, not done; $\mathrm{pCO}$, partial pressure of $\mathrm{CO}_{2} ; R_{\text {tot' }}$, total airway resistance; RV, residual volume; TLC, total lung capacity; pred, predicted. 


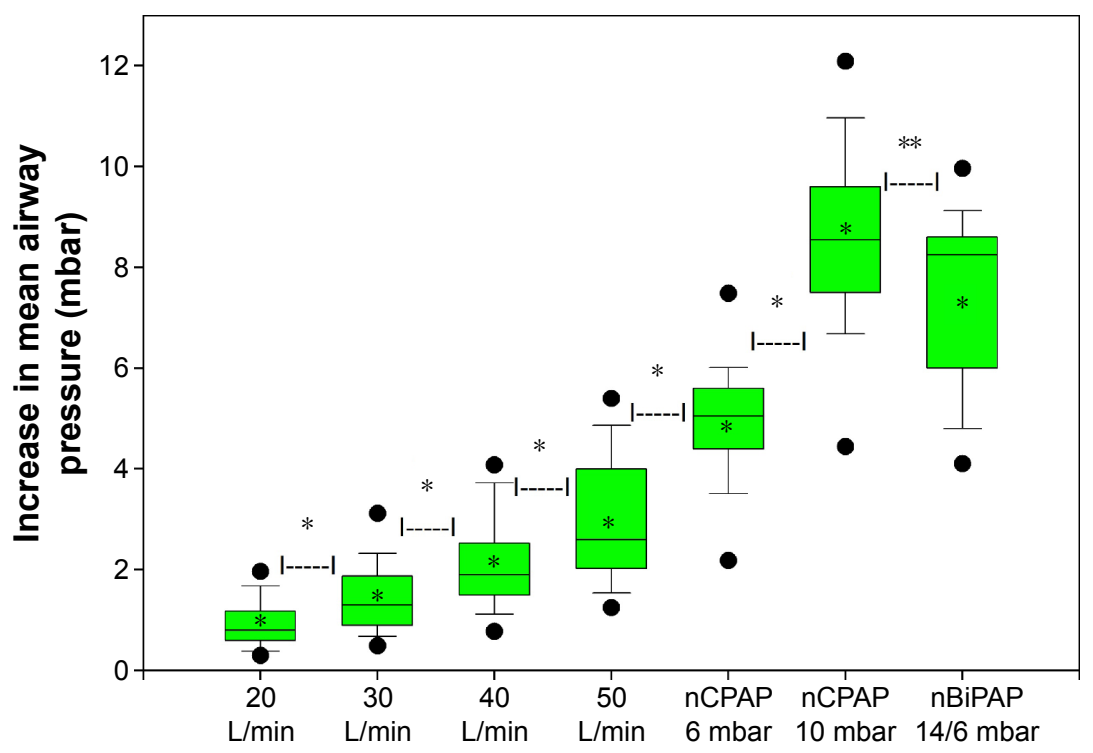

Figure I Changes in mean airway pressure ( $n=19$, medium prong size).

Notes: *Significant $P$-value and $* *$ no significant $P$-value.

Abbreviations: nBiPAP, (nasal) bilevel positive airway pressure; nCPAP, (nasal) continuous positive airway pressure.

nBiPAP ventilatory supports (Table 2 and Figure 1). Between $20 \mathrm{~L} / \mathrm{min}$ and $30 \mathrm{~L} / \mathrm{min}$, a significant increase in mean airway pressure was found $(P<0.03)$ (Figure 1).

\section{Changes in ventilatory parameters}

All ventilation support devices increased significantly the VT compared to spontaneous breathing (NHF, $20 \mathrm{~L} / \mathrm{min}=+93 \mathrm{~mL}$; nCPAP, 6 mbar $=+121.4 \mathrm{~mL}$; nBiPAP, $14 / 6$ mbar $=+165.2 \mathrm{~mL} ; P<0.05)$. No significant differences were observed between different flows, prong sizes, devices, and pressure settings (Table 3 and Figure 2). BR decreased compared to spontaneous breathing when using NHF $(P<0.05)$. Changing prong sizes did not influence BR. With increasing NHF rates, BR tended to further fall, but these changes did not reach statistical significance. This decrease in BR was not observed in nCPAP/nBiPAP (Table 3 and Figure 3). Minute volume was decreased in patients using NHF in contrast to those using nCPAP/nBiPAP, who had increased minute volume $(P<0.05)$ (Table 3 and Figure 4$)$.
Inspiration/expiration ratio was not altered by any of the ventilatory support devices.

\section{Changes in RSBI}

Ventilatory support, regardless of the applied device, caused a significant decrease in RSBI in all groups $(P<0.01)$. An increase in NHF rate appeared to enhance this effect. No difference was observed in the decrease in RSBI in NHF vs nBiPAP/nCPAP (Table 4 and Figure 5).

\section{Comfort and dyspnea scale}

The poorest comfort was found in nCPAP, and the best comfort was found in NHF with medium prongs. Results were similar when patients were asked to report their subjective amount of dyspnea (Table 5).

\section{Blood gas analysis}

NHF breathing led to a significant decrease in hypercapnia. An increase in flow from $20 \mathrm{~L} / \mathrm{min}$ to $30 \mathrm{~L} / \mathrm{min}$ decreased

Table 2 Mean airway pressure - medium prong size

\begin{tabular}{|c|c|c|c|c|c|c|c|}
\hline & 20 L/min & $30 \mathrm{~L} / \mathrm{min}$ & 40 L/min & 50 L/min & $\begin{array}{l}\text { nCPAP } \\
\text { (6 mbar) }\end{array}$ & $\begin{array}{l}\text { nCPAP } \\
\text { (10 mbar) }\end{array}$ & $\begin{array}{l}\text { nBiPAP } \\
\text { (14/6 mbar) }\end{array}$ \\
\hline Mean (mbar) $\pm S D$ & $0.92 \pm 0.49$ & $1.44 \pm 0.78$ & $2.14 \pm 0.98$ & $3.01 \pm 1.03$ & $4.96 \pm 1.34$ & $8.56 \pm 2.02$ & $7.46 \pm 1.77$ \\
\hline$P$-value & $<0.0$ l & $<0.03$ & $<0.03$ & $<0.03$ & $<0.01$ & $<0.01$ & $>0.05$ \\
\hline
\end{tabular}

Notes: $P$-value to refer to zero in case of $20 \mathrm{~L} / \mathrm{min}$, in all other cases in comparison to previous applied device (for instance, $P$-value in nBiPAP describes no significant difference to nCPAP 10 mbar or for instance, a flow rate of $50 \mathrm{~L} / \mathrm{min}$ increases mean airway pressure significantly compared to $40 \mathrm{~L} / \mathrm{min}$ ).

Abbreviations: nBiPAP, (nasal) bilevel positive airway pressure; nCPAP, (nasal) continuous positive airway pressure; SD, standard deviation. 
Table 3 Changes in ventilatory parameters

\begin{tabular}{|c|c|c|c|c|c|c|c|c|}
\hline & $\begin{array}{l}\text { Spontaneous } \\
\text { breathing }\end{array}$ & $20 \mathrm{~L} / \mathrm{min}$ & $30 \mathrm{~L} / \mathrm{min}$ & $40 \mathrm{~L} / \mathrm{min}$ & $50 \mathrm{~L} / \mathrm{min}$ & $\begin{array}{l}\text { nCPAP } \\
\text { (6 mbar) }\end{array}$ & $\begin{array}{l}\text { nCPAP } \\
\text { (10 mbar) }\end{array}$ & $\begin{array}{l}\text { nBiPAP } \\
\text { (14/6 mbar) }\end{array}$ \\
\hline \multicolumn{9}{|l|}{ VT } \\
\hline $\begin{array}{l}\text { Mean }(\mathrm{mL}) \pm S D \\
\text { mean }(\%) \pm S D\end{array}$ & $44 I .2 \pm I 46.2$ & $\begin{array}{l}534.2 \pm 215.2 \\
104.9 \pm 21.4\end{array}$ & $\begin{array}{l}523.7 \pm 228.5 \\
\text { I I } 3.3 \pm 27.6\end{array}$ & $\begin{array}{l}561.7 \pm 248.8 \\
123.2 \pm 27.7\end{array}$ & $\begin{array}{l}558.8 \pm 260.0 \\
123.8 \pm 27.2\end{array}$ & $\begin{array}{l}562.6 \pm 215.7 \\
125.3 \pm 29.4\end{array}$ & $\begin{array}{l}579.3 \pm 262.6 \\
126.8 \pm 28.8\end{array}$ & $\begin{array}{l}606.9 \pm 249.5 \\
133.6 \pm 30.1\end{array}$ \\
\hline$P$-value from mean $(\%)$ & & $<0.01$ & $<0.05$ & $<0.01$ & $<0.01$ & $<0.01$ & $<0.01$ & $<0.01$ \\
\hline \multicolumn{9}{|l|}{ BR } \\
\hline $\begin{array}{l}\text { Mean }(b p m) \pm S D \\
\text { mean }(\%) \pm S D\end{array}$ & $|5.7 \pm 4|$. & $\begin{array}{l}11.6 \pm 3.6 \\
76.6 \pm 17.0\end{array}$ & $\begin{array}{l}11.1 \pm 3.6 \\
73.8 \pm 18.1\end{array}$ & $\begin{array}{l}10.3 \pm 3.3 \\
71.0 \pm 19.1\end{array}$ & $\begin{array}{l}9.9 \pm 2.7 \\
67.9 \pm 14.8\end{array}$ & $\begin{array}{l}14.3 \pm 3.8 \\
94.6 \pm 14.0\end{array}$ & $\begin{array}{l}14.3 \pm 4.3 \\
94.2 \pm 16.3\end{array}$ & $\begin{array}{l}15.4 \pm 4.3 \\
101.6 \pm 18.4\end{array}$ \\
\hline$P$-value from mean (\%) & & $<0.01$ & $<0.01$ & $<0.01$ & $<0.01$ & $>0.05$ & $>0.05$ & $>0.05$ \\
\hline \multicolumn{9}{|l|}{ MV } \\
\hline $\begin{array}{l}\text { Mean } L / \min \pm S D \\
\text { mean }(\%) \pm S D\end{array}$ & $7.1 \pm 2.9$ & $\begin{array}{l}6.0 \pm 2.8 \\
86.6 \pm 14.2\end{array}$ & $\begin{array}{l}5.6 \pm 2.6 \\
83.3 \pm 21.1\end{array}$ & $\begin{array}{l}5.5 \pm 2.5 \\
85.3 \pm 24.0\end{array}$ & $\begin{array}{l}5.4 \pm 2.5 \\
83.7 \pm 24.7\end{array}$ & $\begin{array}{l}7.8 \pm 3.2 \\
117.7 \pm 32.2\end{array}$ & $\begin{array}{l}8.2 \pm 3.8 \\
\text { I } 19.9 \pm 28.6\end{array}$ & $\begin{array}{l}8.9 \pm 3.5 \\
133.7 \pm 36.2\end{array}$ \\
\hline$P$-value from mean (\%) & & $<0.01$ & $<0.01$ & $<0.01$ & $<0.01$ & 0.01 & $<0.01$ & $<0.01$ \\
\hline
\end{tabular}

Note: $P$-values in comparison to spontaneous breathing.

Abbreviations: $\mathrm{BR}$, breathing rate; $\mathrm{MV}$, minute volume-medium prong size; $\mathrm{nCPAP}$, (nasal) continuous positive airway pressure; nBiPAP, (nasal) bilevel positive airway pressure; VT, tidal volume; SD, standard deviation.

$\mathrm{pCO}_{2}$ even more $(P<0.03)$ (Table 6 and Figure 6). These changes occurred despite the decrease in minute volume. $\mathrm{pO}_{2}$ showed no significant differences between baseline and between different flows. The $\mathrm{pH}$ was significantly increased during NHF breathing $(20 \mathrm{~L}=P<0.01 / 30 \mathrm{~L}=P<0.01)$. We found no significant differences in $\mathrm{pH}$ values between different flow rates.

\section{Regression analysis}

Initially elevated $\mathrm{pCO}_{2}$ values were an independent predictor for a greater decrease with NHF therapy (this was true for
$20 \mathrm{~L} / \mathrm{min}$ and $30 \mathrm{~L} / \mathrm{min}$ ). No correlation was observed between the measured drop in $\mathrm{pCO}_{2}$ during NHF breathing and the individual body mass index or lung function parameters.

\section{Discussion}

The present study demonstrates that NHF may improve breathing patterns, decrease the work of breathing (RSBI), and decrease $\mathrm{pCO}_{2}$ levels in patients with stable hypercapnic COPD.

Ventilatory support systems are designed to reduce the work of breathing, ideally, leading to an improvement in

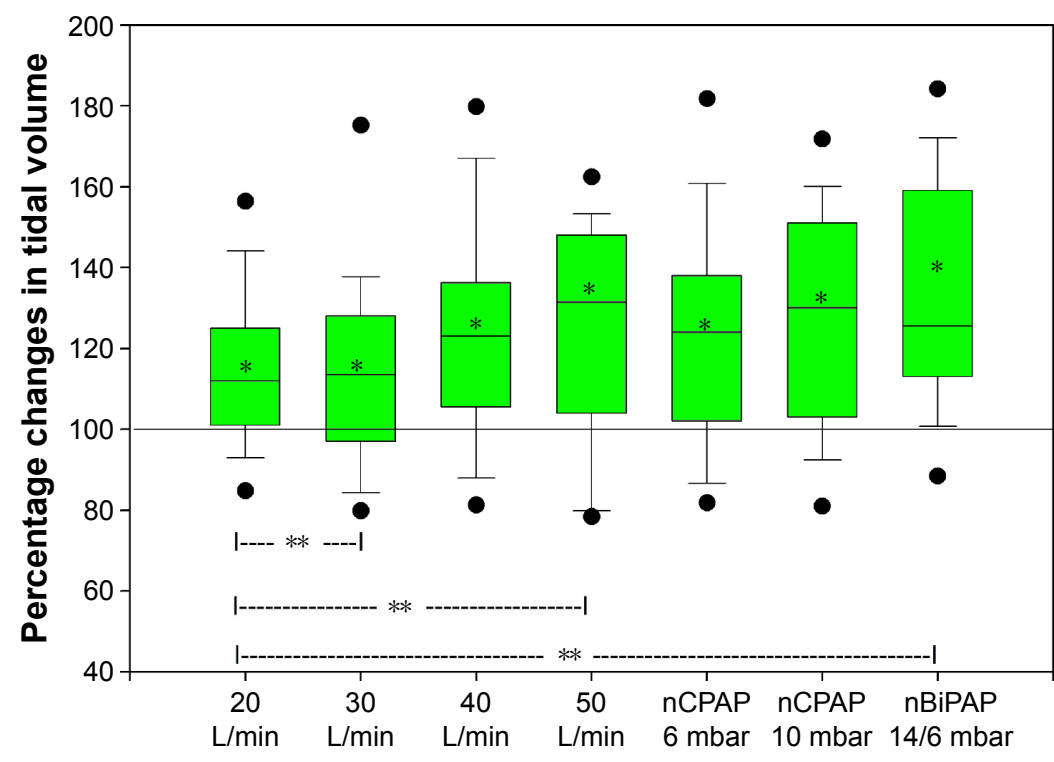

Figure 2 Percentage changes in tidal volume ( $\mathrm{n}=18$, medium prong size).

Notes: *Significant $P$-value and **no significant $P$-value.

Abbreviations: nBiPAP, (nasal) bilevel positive airway pressure; nCPAP, (nasal) continuous positive airway pressure. 


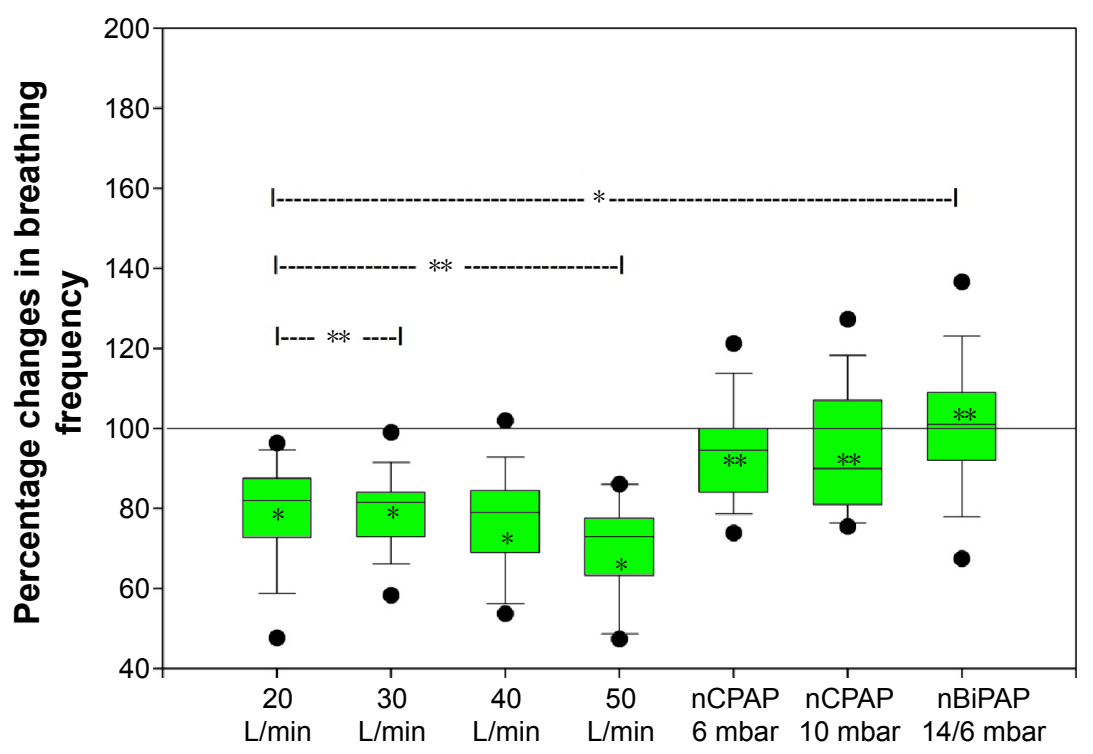

Figure 3 Percentage changes in breathing rate ( $n=18$, medium prong size).

Notes: *Significant $P$-value and **no significant $P$-value.

Abbreviations: nBiPAP, (nasal) bilevel positive airway pressure; nCPAP, (nasal) continuous positive airway pressure.

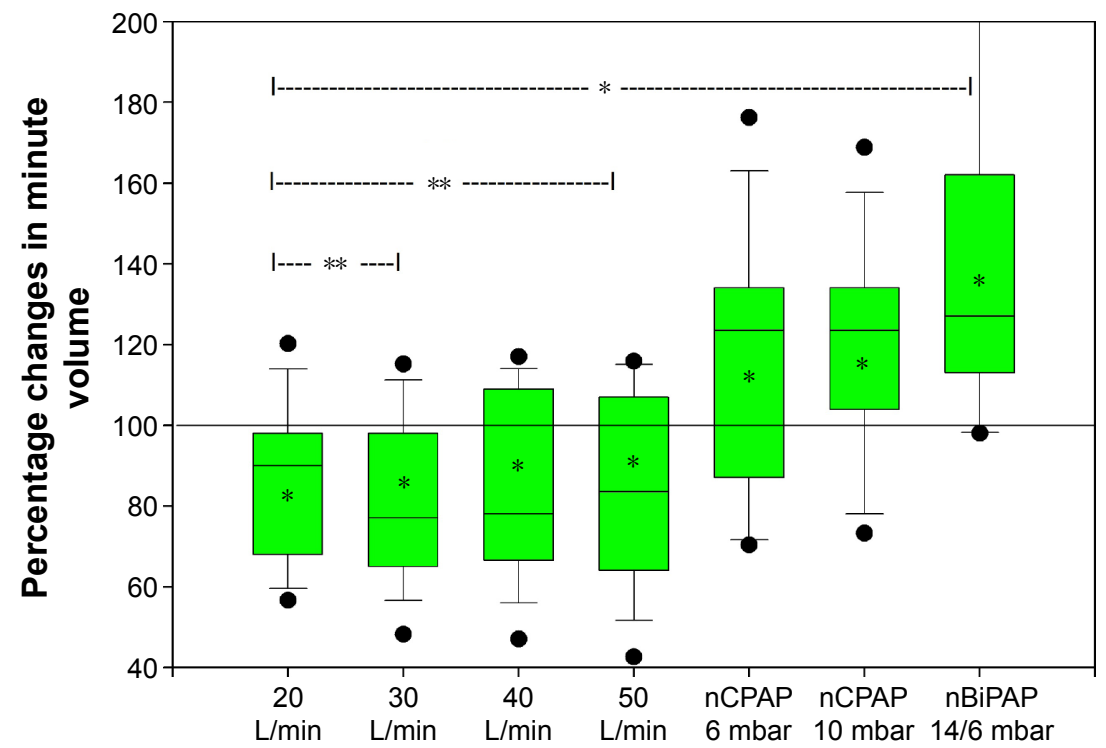

Figure 4 Percentage changes in minute volume ( $n=18$, medium prong size).

Notes: *Significant $P$-value and **no significant $P$-value.

Abbreviations: nBiPAP, (nasal) bilevel positive airway pressure; nCPAP, (nasal) continuous positive airway pressure.

Table 4 RSBI - medium prong size

\begin{tabular}{|c|c|c|c|c|c|c|c|c|}
\hline & $\begin{array}{l}\text { Spontaneous } \\
\text { breathing }\end{array}$ & $20 \mathrm{~L} / \mathrm{min}$ & $30 \mathrm{~L} / \mathrm{min}$ & $40 \mathrm{~L} / \mathrm{min}$ & $50 \mathrm{~L} / \mathrm{min}$ & $\begin{array}{l}\text { nCPAP } \\
\text { (6 mbar) }\end{array}$ & $\begin{array}{l}\text { nCPAP } \\
\text { (10 mbar) }\end{array}$ & $\begin{array}{l}\text { nBiPAP } \\
\text { (14/6 mbar) }\end{array}$ \\
\hline \multicolumn{9}{|l|}{$\mathrm{BR} / \mathrm{VT}$} \\
\hline Mean \pm SD & $41.6 \pm 22.0$ & $27.4 \pm 17.9$ & $28.0 \pm 18.9$ & $25.1 \pm 19.9$ & $25.4 \pm 18.3$ & $32.8 \pm 28.3$ & $32.3 \pm 26.5$ & $32.3 \pm 23.3$ \\
\hline Mean (\%) \pm SD & & $67.9 \pm 24.2$ & $69.2 \pm 25.4$ & $61.9 \pm 29.2$ & $62.3 \pm 40.6$ & $78.0 \pm 25.6$ & $76.3 \pm 29.2$ & $76.9 \pm 29.1$ \\
\hline$P$-value from mean (\%) & & $<0.01$ & $<0.01$ & $<0.01$ & $<0.01$ & $<0.01$ & $<0.01$ & $<0.01$ \\
\hline
\end{tabular}

Note: $P$-value in comparison to spontaneous breathing.

Abbreviations: BR, breathing rate; $\mathrm{nBiPAP}$, (nasal) bilevel positive airway pressure; $\mathrm{nCPAP}$, (nasal) continuous positive airway pressure; RSBI, rapid shallow breathing index; VT, tidal volume; SD, standard deviation. 


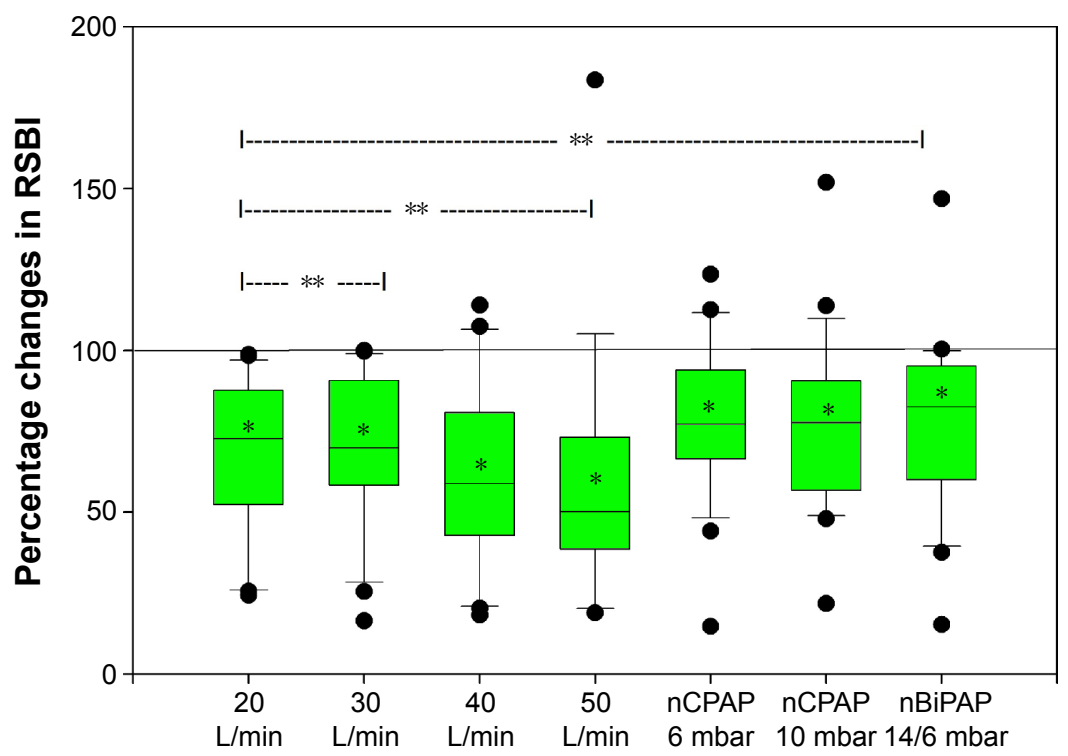

Figure 5 Percentage changes in RSBI ( $n=18$, medium prong size).

Notes: *Significant $P$-value and $*^{*}$ no significant $P$-value.

Abbreviations: nBiPAP, (nasal) bilevel positive airway pressure; nCPAP, (nasal) continuous positive airway pressure; RSBI, rapid shallow breathing index.

blood gases. A decrease in hypercapnia will be an indicator of improved ventilation as well as a decrease in RSBI when previously elevated. RSBI is usually measured in situations of acute respiratory insufficiency, serves as a predictor of weaning success, and determines the need for NIV use in muscular dystrophy. ${ }^{30-33}$ In this study, both nCPAP/nBiPAP and NHF significantly decreased RSBI in patients with COPD. The changes in RSBI in both modes of ventilatory support suggest a similar improvement in the work of breathing in these patients. Interestingly, this is in spite of varying changes in ventilatory parameters among the devices. To our knowledge, this is the first time that this parameter was used for evaluating the effect of NIV and NHF in patients with stable COPD.

Today, it is well known that NHF is able to maintain steady oxygenation in situations of respiratory stress. Compared to other oxygen delivery systems, NHF shows no decrease in

Table 5 Comfort/dyspnea scale

\begin{tabular}{|c|c|c|c|c|c|}
\hline & $\begin{array}{l}\text { NHF } \\
\text { small }\end{array}$ & $\begin{array}{l}\text { NHF } \\
\text { medium }\end{array}$ & $\begin{array}{l}\text { NHF } \\
\text { large }\end{array}$ & nCPAP & nBiPAP \\
\hline \multicolumn{6}{|c|}{ Comfort scale $(I-10)$} \\
\hline Mean $\pm S D$ & $4.3 \pm 1.5$ & $3.4 \pm 1.5$ & $3.9 \pm 2.0$ & $5.4 \pm 1.9$ & $4.4 \pm 2.4$ \\
\hline$P$-value & $<0.05$ & & $>0.05$ & $<0.01$ & $>0.05$ \\
\hline \multicolumn{6}{|c|}{ Dyspnea scale (I-5) } \\
\hline Mean $\pm S D$ & $2.7 \pm 0.7$ & $2.6 \pm 0.9$ & $2.6 \pm 0.9$ & $3.2 \pm 0.7$ & $2.8 \pm 1.1$ \\
\hline$P$-value & $>0.05$ & & $>0.05$ & $<0.01$ & $>0.05$ \\
\hline
\end{tabular}

Note: $P$-values in comparison to NHF with medium prong size.

Abbreviations: nBiPAP, (nasal) bilevel positive airway pressure; nCPAP, (nasal) continuous positive airway pressure; NHF, nasal highflow; SD, standard deviation. endobronchial oxygen concentration during higher BRs. This tends to result in stable oxygenation values. ${ }^{19}$ Nevertheless, NHF is able to influence ventilatory parameters. ${ }^{18}$

$\mathrm{nBiPAP} / \mathrm{nCPAP}$ leads to an increase in VT and minute ventilation. On the other hand, patients supported with NHF presented a different pattern - although VT also increased, a decrease in BR was noted resulting in a decrease in minute volume despite the increased VT. Similar findings were reported by Brack et $\mathrm{al}^{34}$ indicating that minute ventilation and BR decreased more with the use of a high flow transtracheal catheter compared to lower flow rates.

An increase in flow resulted in an increased airway pressure in NHF and nCPAP/nBiPAP. However, an increase in flow rate in case of NHF translated to a merely small increase in upper airway pressure, and this subtle pressure increase is not likely to be solely responsible for the observed improvement in ventilation. This is particularly evident when different NHF rates are compared. A small pressure increase of $0.5 \mathrm{mbar}$ (increase in NHF from $20 \mathrm{~L} / \mathrm{min}$ to $30 \mathrm{~L} / \mathrm{min}$ )

Table $6 \mathrm{pCO}_{2}$ changes compared to baseline - medium prong size

\begin{tabular}{lll}
\hline & $20 \mathrm{~L} / \mathrm{min}$ & $30 \mathrm{~L} / \mathrm{min}$ \\
\hline $\mathrm{PCO}_{2}$ & & \\
Mean (\%) $\pm \mathrm{SD}$ & $91 \pm 6.7$ & $87.4 \pm 6.2$ \\
$P$-value in comparison to & $<0.01$ & $<0.01$ \\
spontaneous breathing & & \\
$P$-value between different flow rates & \multicolumn{2}{c}{$<0.03$} \\
\hline
\end{tabular}

Note: $P$-values in comparison between different flow rates and baseline. Abbreviations: $\mathrm{pCO}_{2}$, partial pressure of $\mathrm{CO}_{2}$; $\mathrm{SD}$, standard deviation. 


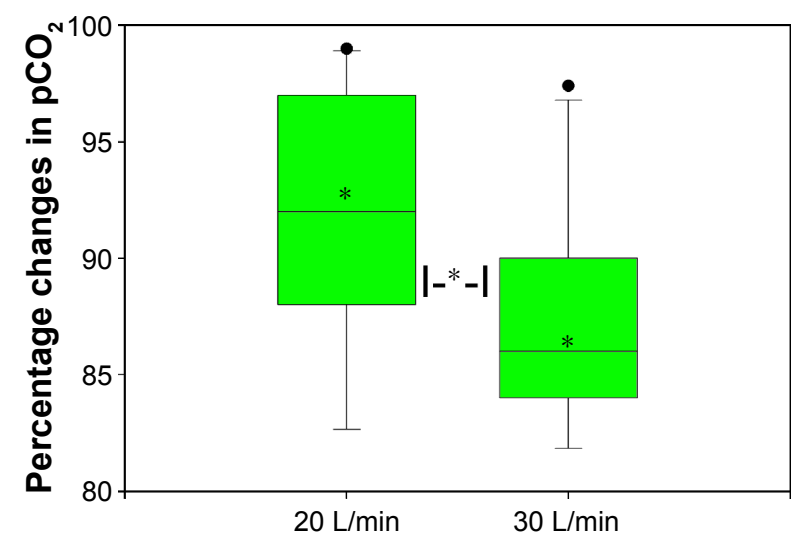

Figure 6 Percentage changes in $\mathrm{pCO}_{2}$ after 2 hours of NHF breathing $(n=54$, medium prong size).

Note: *Significant $P$-value.

Abbreviations: NHF, nasal highflow; $\mathrm{PCO}_{2}$, partial pressure of $\mathrm{CO}_{2}$.

will hardly be effective in recruiting significant amounts of previously closed alveoli but may help to keep a fraction of the smaller collapsing airways open.

Higher air flow (eg, $20 \mathrm{~L} / \mathrm{min}$ vs $30 \mathrm{~L} / \mathrm{min} \mathrm{NHF}$ ), instead of an increase in pressure, increases the amount of air, washing out the resident gas mixture in the upper airways by $50 \%$. This relatively large increase will be more effective in replacing exhaled air with fresh air with low $\mathrm{pCO}_{2}$, thus diminishing the amount of exhaled gas that is rebreathed (ie, a reduction in dead space). The reduction in reinhaled $\mathrm{CO}_{2}\left(\sim 5 \%\right.$ in the exhaled) will increase the amount of $\mathrm{CO}_{2}$ eliminated with each breath. Washout being an important aspect of NHF has conclusively been demonstrated by Frizzola et $\mathrm{a}^{29}$ in an animal model, where $\mathrm{pCO}_{2}$ was best eliminated with NHF when leakage (from the upper airways) was increased. The effectiveness of exhaled air washout has also been demonstrated in an elaborate model of the upper airways with radioactive tracer gas and NHF connected to this artificial nose and upper airway. ${ }^{35}$ The exhaled gas washout hypothesis explains best how an increase in VT and a concomitant decrease in minute volume lead to a reduction in hypercapnia.

NIV has been shown to reduce $\mathrm{pCO}_{2}{ }^{3}$ For NHF, this has not yet been demonstrated in a similar manner, but initial reports indicate that NHF may also result in efficient reduction in hypercapnia. ${ }^{18}$ The decrease in hypercapnia was also shown in a long time setting in comparison with NIV. ${ }^{17}$ In this preliminary study, no differences in capillary $\mathrm{pCO}_{2}$ between NHF and NIV were found. The decrease in hypercapnia after 6 weeks of use was significant. ${ }^{18}$ If these results would be confirmed by a larger study, NHF should be considered and further evaluated as a ventilatory support device.

\section{Limitations}

We recognize several limitations of this study. Patients in this study were not randomized, but measurements were done according to a program in order to evaluate various conditions. Not all patients of the pressure and volume groups were hypercapnic. However, the functional data are similar within these three groups (Table 1). Only few patients completed all of the interventions. The time spent on the various conditions of ventilatory support was rather short. The nCPAP/nBiPAP group, in particular, may not have been able to get sufficiently accustomed to their treatment modality. To relieve adaptation on CPAP/BiPAP, we used nasal masks instead of nasobuccal masks. Data and $P$ values of ventilatory measurements and $\mathrm{pCO}_{2}$ changes were presented as percentage changes because of wide variations in baseline between patients.

\section{Conclusion}

NHF leads to flow-dependent reduction in $\mathrm{pCO}_{2}$. VT increased and minute volume decreased with $\mathrm{pCO}_{2}$ surprisingly reduced to more normal values. This is most likely achieved by a washout of the respiratory tract and a functional reduction in dead space. The increase in pressure may have various effects such as opening a smaller fraction of otherwise closed alveoli and small airways, but the effect is small and not comparable to the pressure increase induced by $\mathrm{nCPAP} / \mathrm{nBiPAP}$. In summary, NHF intensifies the effectiveness of breathing in patients with COPD and reduces $\mathrm{pCO}_{2}$, the work of breathing, and RSBI as an indicator of respiratory work load. These results could open up the possibility to compare NHF and NIV in acute exacerbation of COPD.

\section{Author contributions}

All authors contributed toward data analysis, drafting and critically revising the paper and agree to be accountable for all aspects of the work.

\section{Disclosure}

JB received travel grants and equipment from TNI medical AG, MK declared no competing interests, and HW received presentation lecture fees from TNI medical AG. The authors report no other conflicts of interest in this work.

\section{References}

1. Wijkstra PJ, Lacasse Y, Guyatt GH, Goldstein RS. Nocturnal non-invasive positive pressure ventilation for stable chronic obstructive pulmonary disease. Cochrane Database Syst Rev. 2002;(3):CD002878. 
2. Struik FM, Lacasse Y, Goldstein R, Kerstjens HM, Wijkstra PJ. Nocturnal non-invasive positive pressure ventilation for stable chronic obstructive pulmonary disease. Cochrane Database Syst Rev. 2013;6: CD002878.

3. Dreher M, Storre JH, Schmoor C, Windisch W. High-intensity versus low-intensity non-invasive ventilation in patients with stable hypercapnic COPD: a randomised crossover trial. Thorax. 2010;65(4): 303-308

4. Windisch W, Haenel M, Storre JH, Dreher M. High-intensity noninvasive positive pressure ventilation for stable hypercapnic COPD. Int J Med Sci. 2009;6(2):72-76.

5. Köhnlein T, Windisch W, Köhler D, et al. Non-invasive positive pressure ventilation for the treatment of severe stable chronic obstructive pulmonary disease: a prospective, multicentre, randomised, controlled clinical trial. Lancet Respir Med. 2014;2(9):698-705.

6. Criner GJ, Brennan K, Travaline JM, Kreimer D. Efficacy and compliance with noninvasive positive pressure ventilation in patients with chronic respiratory failure. Chest. 1999;116(3):667-675.

7. Benhamou D, Girault C, Faure C, Portier F, Muir JF. Nasal mask ventilation in acute respiratory failure. Experience in elderly patients. Chest. 1992;102(3):912-917.

8. Navalesi P, Fanfulla F, Frigerio P, Gregoretti C, Nava S. Physiologic evaluation of noninvasive mechanical ventilation delivered with three types of masks in patients with chronic hypercapnic respiratory failure. Crit Care Med. 2000;28(6):1785-1790.

9. Mehta S, Hill NS. Noninvasive ventilation. Am J Respir Crit Care Med. 2001;163(2):540-577.

10. Schönhofer B, Sortor-Leger S. Equipment needs for noninvasive mechanical ventilation. Eur Respir J. 2002;20(4):1029-1036.

11. Nava S, Navalesi P, Gregoretti C. Interfaces and humidification for noninvasive mechanical ventilation. Respir Care. 2009;54(1):71-84.

12. Sreenan C, Lemke RP, Hudson-Mason A, Osiovich H. High-flow nasal cannulae in the management of apnea of prematurity: a comparison with conventional nasal continuous positive airway pressure. Pediatrics. 2001 107(5):1081-1083.

13. Shoemaker MT, Pierce MR, Yoder BA, DiGeronimo RJ. High flow nasal cannula versus nasal CPAP for neonatal respiratory disease: a retrospective study. J Perinatol. 2007;27(2):85-91.

14. McGinley B, Halbower A, Schwartz AR, Smith PL, Patil SP, Schneider H. Effect of a high-flow open nasal cannula system on obstructive sleep apnea in children. Pediatrics. 2009;124(1):179-188.

15. Spence KL, Murphy D, Kilian C, McGonigle R, Kiliani RA. High-flow nasal cannula as a device to provide continuous positive airway pressure in infants. J Perinatol. 2007;27(12):772-775.

16. Kubicka ZJ, Limauro J, Darnall RA. Heated, humidified high-flow nasal cannula therapy: yet another way to deliver continuous positive airway pressure? Pediatrics. 2008;121(1):82-88.

17. Bräunlich J, Seyfarth HJ, Wirtz H. Nasal high-flow versus noninvasive ventilation in stable hypercapnic COPD: a preliminary report. Multidiscip Respir Med. 2015;10(1):27.

18. Bräunlich J, Beyer D, Mai D, Hammerschmidt A, Seyfarth HJ, Wirtz H. Effects of nasal high flow on ventilation in volunteers, COPD and idiopathic pulmonary fibrosis patients. Respiration. 2013;85(4):319-325.
19. Maggiore SM, Idone FA, Vaschetto R, et al. Nasal high-flow versus venturi mask oxygen therapy after extubation. Effects on oxygenation, comfort and clinical outcome. Am J Respir Crit Care Med. 2014;190(3): 282-288.

20. Frat JP, Thille AW, Mercat A, et al; FLORALI Study Group, REVA Network. High-flow oxygen through nasal cannula in acute hypoxemic respiratory failure. $N$ Engl J Med. 2015;372(23):2185-2196.

21. Roca O, Riera J, Torres F, Masclans JR. High-flow oxygen therapy in acute respiratory failure. Respir Care. 2010;55(4):408-413.

22. Lenglet H, SztrymfB, Leroy C, Brun P, Dreyfuss D, Ricard JD. Humidified high flow nasal oxygen during respiratory failure in the emergency department: feasibility and efficacy. Respir Care. 2012;57(11):1873-1878.

23. Sztrymf B, Messika J, Bertrand F, et al. Beneficial effects of humidified high flow nasal oxygen in critical care patients: a prospective pilot study. Intensive Care Med. 2011;37(11):1780-1786.

24. Sztrymf B, Messika J, Mayot T, Lenglet H, Dreyfuss D, Ricard JD. Impact of high-flow nasal cannula oxygen therapy on intensive care unit patients with acute respiratory failure: a prospective observational study. J Crit Care. 2012;27(3):324.e9-e13.

25. Chatila W, Nugent T, Vance G, Gaughan J, Criner GJ. The effects of high-flow vs low-flow oxygen on exercise in advanced obstructive airways disease. Chest. 2004;126(4):1108-1115.

26. Groves N, Tobin A. High flow nasal oxygen generates positive airway pressure in adult volunteers. Aust Crit Care. 2007;20(4):126-131.

27. Parke R, McGuinness S, Eccleston M. Nasal high-flow therapy delivers low level positive airway pressure. Br J Anaesth. 2009;103(6): 886-890.

28. Dysart K, Miller TL, Wolfson MR, Shaffer TH. Research in high flow therapy: mechanisms of action. Respir Med. 2009;103(10):1400-1405.

29. Frizzola M, Miller TL, Rodriguez ME, et al. High-flow nasal cannula: impact on oxygenation and ventilation in an acute lung injury model. Pediatr Pulmonol. 2011;46(1):67-74.

30. Berg KM, Lang GR, Salciccioli JD, et al. The rapid shallow breathing index as a predictor of failure of noninvasive ventilation for patients with acute respiratory failure. Respir Care. 2012;57(10):1548-1554.

31. Yang KL, Tobin MJ. A prospective study of indexes predicting the outcome of trials of weaning from mechanical ventilation. $N$ Engl J Med. 1991; 324(21):1445-1450.

32. Toussaint M, Steens M, Soudon P. Lung function accurately predicts hypercapnia in patients with Duchenne muscular dystrophy. Chest. 2007; 131(2):368-375.

33. Hamada S, Ishikawa Y, Aoyagi T, Ishikawa Y, Minami R, Bach JR. Indicators for ventilator use in Duchenne muscular dystrophy. Respir Med. 2011;105(4):625-629.

34. Brack T, Senn O, Russi EW, Bloch KE. Transtracheal high-flow insufflation supports spontaneous respiration in chronic respiratory failure. Chest. 2005;127(1):98-104.

35. Möller W, Celik G, Feng S, et al. Nasal high flow clears anatomical dead space in upper airway models. J Appl Physiol (1985). 2015;118(12): 1525-1532.
International Journal of COPD

\section{Publish your work in this journal}

The International Journal of COPD is an international, peer-reviewed journal of therapeutics and pharmacology focusing on concise rapid reporting of clinical studies and reviews in COPD. Special focus is given to the pathophysiological processes underlying the disease, intervention programs, patient focused education, and self management protocols.

\section{Dovepress}

This journal is indexed on PubMed Central, MedLine and CAS. The manuscript management system is completely online and includes a very quick and fair peer-review system, which is all easy to use. Visit http://www.dovepress.com/testimonials.php to read real quotes from published authors. 